\title{
El concepto de Märchen (cuento maravilloso) en la obra temprana de György Lukács
}

\section{The Concept of Märchen (Fairy Tale) in the Young György Lukács}

\section{0 conceito de Märchen (conto de fadas) no pensamento do jovem Lukács}

\author{
iD Francisco Garcia Chicote. \\ Universidade de Buenos Aires (UBA), Cidade Autônoma de Buenos Aires, Argentina \\ E-mail: fgchicote@gmail.com.
}

\begin{abstract}
Resume: Se parte aquí del presupuesto de que la categoría de Märchen (cuento maravilloso) ofrece una clave de acceso al intrincado pensamiento temprano de György Lukács. La perspectiva ilumina en efecto toda una problemática normalmente desatendida: el intento, por parte del joven filósofo, de superar el estricto dualismo del incipiente pensamiento sociológico alemán y de probar intelectualmente la posibilidad de una existencia digna. Esto no solo enfrenta al Märchen con el ethos de la tragedia en el temprano concepto lukácsiano de género literario; también lo convierte en una suerte de "piedra de toque" en la búsqueda de formas de la literatura que presupongan una relación sujeto-objeto de condicionamiento recíproco y, además, en una herramienta para un programa pedagógico revolucionario.
\end{abstract}

Palabras clave: Marxismo occidental. Teoría de los géneros literarios. Crítica de la cultura.

Abstract: The article examines György Lukács's early works from the perspective of his concept of Märchen (fairy tale). It thus sheds light upon 
a somewhat underexplored - but nonetheless crucial - aspect of the young philosopher's work: his attempt to overcome the strict dualism in which the emerging German sociological thought was rooted, and to intellectually prove the possibility of a dignified human existence. Such an attempt does not only confront the concepts of Märchen and tragedy in Lukács' early conceptualization of literary genres, it also turns the former into a sort of "touchstone" in the search of forms of literature that assume a dialectically conditioned relationship between subject and object, and, furthermore, into an adequate means for a revolutionary pedagogy.

Keywords: Western Marxism. Theory of Literary Genres. Critique of Culture.

Resumo: Partiremos do pressuposto de que a categoria Märchen (conto de fadas) oferece uma chave de interpretação para o intrincado pensamento do jovem Lukács. Essa perspectiva ilumina, com efeito, uma problemática normalmente esquecida: a intenção, por parte do jovem filosófico, de superar o rígido dualismo do incipiente pensamento sociológico alemão e de provar intelectualmente a possibilidade de uma existência digna. Por isso, ele não apenas confronta a Märchen com o ethos da tragédia a partir do nascente conceito lukacsiano de gênero literário, mas também o converte em uma espécie de "pedra de toque" na busca de formas literárias que pressuponham uma relação sujeitoobjeto de condicionamento recíproco, além de torná-la um instrumento para o programa pedagógico revolucionário.

Palavras-chave: Marxismo ocidental. Teoria dos gêneros literários. Crítica da cultura.

Submetido em 31 de agosto de 2020.

Aceito em 29 de setembro de 2020.

Publicado em 11 de janeiro de 2021. 
El concepto de Märchen (cuento maravilloso) en la obra temprana de György Lukács Francisco Garcia Chicote

\section{Introducción}

Las reflexiones sobre el Märchen ${ }^{1}$ en la ensayística temprana de Lukács parecen exiguas, ambiguas, difusas, incluso contradictorias. Acaso por ello, el tema recibió escasa atención crítica. Su relevancia empero fue advertida por Miguel Vedda (2011 y 2015) y Gábor Gángó (2014) en contribuciones sobre el desarrollo intelectual del joven filósofo y sobre el lugar del Märchen en los escritos de intelectuales alemanes del "marxismo occidental". Vedda y Gángó ubicaron las consideraciones lukácsianas sobre el género en cuestión dentro de los intentos del filósofo por superar el propio carácter trágico que caracteriza parte de su producción; asimismo, llamaron la atención sobre el rol que el Märchen desempeñó en las políticas educativas de la breve República de los consejos húngara de 1919 -al mando de cuyo Comisariado popular de educación se hallaba Lukács- y sobre la proximidad con teorizaciones posteriores, presentes en las obras de Walter Benjamin, Siegfried Kracauer y Ernst Bloch. En lo que concierne a estos dos últimos aspectos, Gángó (2014, p. 55s.) afirma que "el punto de partida y [el] objetivo" de Lukács y los intelectuales de izquierda alemanes "era desarrollar la utopía a partir del ideario de la sociedad precientífica mediante los Märchen".

Como señala Vedda (2015, p. 63), la temprana definición lukácsiana de Märchen también anticiparía en cierta medida elementos del desarrollo ulterior del filósofo. De la celebración de la vida cotidiana que supone la poética de este género se deduciría un principio que ejercería "una función cardinal en la estética madura: el arte 'grande' presenta al mundo no como una realidad alienada y hostil, sino como el resultado de una interacción dialéctica, en la cual desempeñan un papel esencial las tomas de posición concretas del ser humano".

\footnotetext{
1 Si bien "Märchen" significa "cuento maravilloso", nos referimos a este fenómeno en su voz alemana porque ella retiene cierta ambigüedad de significado que, como veremos, recorre las reflexiones del propio Lukács. Provisoriamente tómese la definición circular de André Jolles (1956, p. 182): “un Märchen es un relato o una historia tal como los hermanos Grimm la han antologizado en su obra Kinder- und Hausmärchen".
} 
El concepto de Märchen (cuento maravilloso) en la obra temprana de György Lukács Francisco Garcia Chicote

La reciente edición, en 2018, del primer tomo de los Werke de Lukács, que reúne documentos inéditos y olvidados de su producción temprana, arroja nueva luz sobre el objeto habilitado por Vedda y Gángó. Por un lado, estos documentos revelan caracterizaciones más concretas de la noción de Märchen al interior de la teoría lukácsiana de los géneros literarios; por el otro, muestran nuevas conexiones entre esta noción y las teorías política, pedagógica y sociológica del filósofo, al punto que deviene pertinente una continuación de la investigación comenzada por los trabajos mencionados. Las siguientes líneas quieren reconstruir el concepto de Märchen en la obra de Lukács entre 1910 y 1919. El arco temporal indica, en un extremo, las primeras apariciones del problema, sumidas en la discusión en torno a la posibilidad de la felicidad humana; en el otro, señala el momento en que el Märchen apuntala la pedagogía revolucionaria del Comisariado popular de educación.

En consonancia con los trabajos anteriores, se verá que, a pesar de su apariencia evanescente, el concepto de Märchen impulsa una crítica radical de la sociedad burguesa que, por un lado, pone en entredicho el dualismo subjetivista con el que el incipiente pensamiento sociológico centroeuropeo comprendía el proceso de socialización y, por el otro, atisba en los géneros épicos un modelo de dinámica existencial auténticamente humana. A la luz de los documentos nuevamente disponibles por la reciente edición del tomo 1 de los Werke se verá, no obstante, que la potencia teórica del concepto de Märchen se funda en una supuesta autonomía absoluta del género, cuyas formas se colocan fuera de la historia y la sociedad. Al no incorporar en dicha conceptualización aspectos mediadores con la realidad que impugna, las reflexiones sobre el Märchen no logran abandonar el dudoso terreno de un deber-ser subjetivo y caen en vacilaciones internas insolubles. De ese modo, muestran afinidades y paralelismos con la primera teoría política del joven filósofo húngaro.

La exposición se divide en cuatro tramos. Se recuperan, en primer lugar, caracteres básicos de la teoría lukácsiana de la 
El concepto de Märchen (cuento maravilloso) en la obra temprana de György Lukács Francisco Garcia Chicote

tragedia en tanto expresión paradigmática de una cosmovisión dualista y pesimista del mundo. En segunda instancia, se rastrea la emergencia terminológica del Märchen en los elementos del corpus hasta 1918 con el fin de reconstruir su concepto. En tercer término, se examina el único ensayo de Lukács, publicado en 1918, que está dedicado exclusivamente a la comprensión del Märchen como género. Finalmente, se analiza el rol asignado al Märchen en los proyectos formativos del Comisariado revolucionario en 1919.

\section{Forma y alienación en la cosmovisión dualista del jo- ven Lukács}

El interés del joven Lukács por el Märchen arraiga en el terreno de sus reflexiones sobre la esencia de los géneros literarios y los diversos modos con los que estos tratarían el carácter alienado del mundo burgués. En 1906, Lukács recurre a una suerte de teoría ontogenética de las artes en tanto especialización de los sentidos e insiste en la centralidad de la forma. Cuando surgieron las artes,

[c]ada una concentró todas sus fuerzas en un ámbito, para desplegar allí, por medio de una concentrada intensidad de sentimiento, su efecto sugestivo e impresionante. [...] La forma nació a partir de esta renuncia. El estrechamiento del espacio, la restricción de los medios de expresión en beneficio de la intensidad de la expresión: eso es la forma (GLW 1, p. 64).

La forma asume un elemento restrictivo propio del medium en el que se desarrolla. A su vez, en virtud de esta negación, la diversidad del mundo se reconfigura artísticamente de modo homogéneo e intensificado. Restricción, homogeneización e intensificación repercuten peculiarmente sobre el plano de la cotidianidad porque esta posee determinaciones precisamente opuestas. Conocido es el pasaje de El alma y las formas (1911) que 
El concepto de Märchen (cuento maravilloso) en la obra temprana de György Lukács Francisco Garcia Chicote

define la vida cotidiana en términos de una caótica variación de grises tonalidades (LUKÁCS, 1985a, p. 170). La forma estética dota de sentido a la indeterminación de la vida diaria. Cada género tiene un "principium stilisationis" que provee empero un haz estrechamente determinado de sentidos -"["I] que en una forma de arte es viable es muerto en las demás" (IBÍD., p. 22)- que se coloca a una distancia igualmente determinada de la estructura del mundo. En cierta medida, cada género representa, por medio de la restricción, la homogeneización y la intensificación que le son propias, no solo un aspecto del mundo, sino más bien una cierta relación sujeto-objeto de la cual puede desprenderse un régimen de vida. Lukács presenta en 1916 esta relación entre género y ética:

Cada forma de la poesía [Dichtung] interroga la esencia del ser humano, y su significancia vital reside en que condensa [verdichten] la en sí caótica confusión de voluntad y sensación, de pensamiento y acción, de impresión y expresión en una sustancia llena de sentido de un yo real, de un "alma". [...] Y las formas se diferencian entre sí conforme el tipo y grado de esta sustancialidad que adquiere el "alma" configurable en ellas (GLW 1, p. 609).

El "grado de sustancialidad" del "alma configurable" en cada principio de estilización se prueba en el modo con que este resuelve el irremediable dualismo que se da entre el alma y la vida. Lukács visita aquí aquella cosmovisión que entiende las alienaciones modernas en términos de un conflicto invariable, metafísicamente arraigado y creciente entre "cultura" y "civilización", entre el impulso formativo del alma y los elementos obstaculizadores de los medios que esta necesariamente crea para sí. Tal contraposición irresoluble entre un principio subjetivo ontológicamente prioritario y el mundo objetivo se halla en las bases de la sociología alemana en formación. ${ }^{2}$

\footnotetext{
2 Piénsese en las múltiples definiciones de Georg Simmel acerca de la "tragedia" de la cultura (cf. GSG 6, pp. 620-654). Apoyándose en un artículo de Kurt Lenk (1964) sobre la conciencia trágica de la sociología alemana, Jörg Kammler rastrea en la obra temprana de Lukács una formulación "específicamente irracional" de la teoría marxiana de la alienación. En la medida en que se funda sobre una separación irrebasable entre esferas polítco-civilizatoria y anímica-axiológica, "Lukács sigue [...] la intención metodológica de Simmel" (1974, pp. 19-21).
} 
El concepto de Märchen (cuento maravilloso) en la obra temprana de György Lukács Francisco Garcia Chicote

De esta cosmovisión se desprende un subjetivismo abstracto cuyo mayor grado de sustancialidad es provisto por la tragedia. En tanto drama paradigmático, la tragedia afirma la soledad del héroe y le permite "consumar de manera gloriosa su yo propio, eterna y apriorísticamente inmanente exclusivamente a partir de sus propias fuerzas" (GLW 1, p. 609). Con esto, Lukács habría formulado los presupuestos para una perspectiva existencialista: "La muerte es aquí meramente una conditio sine qua non", afirma Ferenc Fehér al respecto (1980, p. 246); puesto que las representaciones más adecuadas de la vida solo pueden culminar en la muerte, nuestra conducta vital debe responder a ella afirmativamente. Consecuentemente, la forma se contrapone al mundo como elemento metafísico: de ahí su ahistoricidad, de ahí su idealidad, de ahí también su inequívocamente invariable carácter letal. La forma, concluye Lukács en su ensayo sobre la metafísica de la tragedia (1985a, p. 271), "es el juez supremo de la vida". Es manifiesto el neokantismo de esta definición: Lukács entiende la forma trágica como "forma de la forma", la forma del "yo inteligible", "su postulado tensado hasta lo absoluto" (2015, p. 142).

\section{El Märchen como alternativa a la concepción dualista}

No obstante, no domina completamente el paradigma trágico en la ensayística del joven Lukács. György Márkus (1977) ha mostrado que esta constituye más bien un ejercicio teórico en el que respectivamente son puestas a prueba -extremadas, ensayadasdos posiciones contradictorias y plausibles: que la historia es un agudizamiento del conflicto irrebasable entre el individuo y sus formaciones o, por el contrario, que dicho conflicto es histórico y por lo tanto susceptible de cambiar: o la historia es trágica o la tragedia es histórica. El "dilema ideológico" que impulsaría estos escritos se plasmaría, de acuerdo con Márkus, en "la pregunta de si el estado actual de las cosas [...] era una expresión de la tragedia 
El concepto de Märchen (cuento maravilloso) en la obra temprana de György Lukács Francisco Garcia Chicote

existencial-ontológica de la cultura o simplemente una expresión de sus crisis histórica y por ende resoluble" (1977, p. 99). En efecto, Lukács desarrolló casi en paralelo un concepto opuesto de forma artística, que otorgaba cierta exclusividad al fundamento histórico y por ende al condicionamiento social de esta; así, por ejemplo, considera en su Historia evolutiva del drama moderno a la forma moderna del drama como expresión del proceso de racionalización burguesa (GLW 15, p. 54ss.).

Frente a esta situación, el Märchen procura un tertium datum. En efecto, se perfila como principio rector en una serie de ensayos que, entre 1910 y 1918, ponen en entredicho la inexorabilidad de la miseria humana y afirman la estructura unitaria del mundo, a la vez que no sucumben ante a una reducción sociologista de las formas.

El problema ocupaba a Lukács y a sus colegas húngaros Anna Lesznai y Béla Balázs ya desde 1910. En una carta a Lukács de finales de mayo de ese año, y en ocasión del recién publicado ensayo "Cultura estética", Balázs vincula el escribir cuentos maravillosos con la afirmación, propuesta en aquel ensayo, de la unidad del mundo. En "Cultura estética", Lukács arremetía contra los pilares de la sociología alemana en formación: denunciaba por falsa la presunta libertad del alma, develaba el carácter "frívolo" del ethos trágico y abogaba por un concepto de totalidad dialéctica en el que el polo objetivo parecía ostentar prioridad (LUKÁCS, 2015, pp. 185200). En su carta, Balázs le reprocha no haber profundizado en la noción de unidad, "simbolizada" por los Märchen. Parafraseando al Shakespeare de The Tempest, agrega:

Todo está hecho del mismo material: "sentimiento y paisaje", la idea y los acontecimientos que se consuman en torno a mí, sueño y realidad, todos son UN material. [...] Por ello escribo cuentos maravillosos. [...] A través de su forma, ellos simbolizan que la montaña de cristal al final del mundo no acarrea ningún dualismo en mi mundo (en LUKÁCS, 1982, p. 123s.). 
El concepto de Märchen (cuento maravilloso) en la obra temprana de György Lukács Francisco Garcia Chicote

La comprensión de que el Märchen se halla en cierto modo "por fuera" del desgarramiento de la cultura/civilización e indica de un mundo unitario tiene su antecedente en las teorías románticas, ante todo en Novalis (cf. MAYER y TISMAR, 2003, pp. 65s.), pero se halla impulsada por formas sociohistóricas propias de la Europa central de comienzos del siglo XX. Abreva en el solapamiento, extendido en el ámbito intelectual de entonces, de los conceptos de alienación, cosificación e, incluso, objetividad en general (cf. LUKÁCS, 1969, p. XXVss.), así como en la igualmente extendida convicción de que la superación de la miseria burguesa cobraría el carácter de una redención, un cambio sin transiciones de rasgos religiosos que restituiría un estado perdido, pero ubicuamente latente, de justicia (cf. LÖWY, 1997). De hecho, un mesianismo "ateo" nutría las discusiones del grupo de Lukács (cf. GÁNGÓ, 2015 y BALÁZS, 1972, p. 124ss.).

En un encuentro con Lukács en 1912, Lesznai concibe el Märchen como prueba de la inmanencia del principio divino. Su divinidad provendría, en primer lugar, de que el género reconoce la posibilidad como categoría fundamental del mundo; en segundo lugar, de que la esencia del Märchen sería lo puramente correcto, algo que Lesznai concibe como una determinación de Dios; y, finalmente, de su facultad dispensadora de justicia, restitutiva de derechos a todas las cosas: "al dignificar todo (animales, árboles, etc.) para consagrarlo como portador de la verdad de Dios, [el Märchen] les devuelve a las cosas su valor originario" (LESZNAI, 1985, p. 130).

También Lukács concebía el Märchen como representación de un mundo unitario, contrapuesto al presunto dualismo de la existencia. Característica de sus reflexiones es empero una vacilación, que asoma desde el comienzo en sus trabajos y que será resuelta recién en 1919: la pregunta de si el mundo utópico del Märchen puede cobrar o no realidad empírica. En buena medida, se trata de aquel "dilema" indicado arriba. En la trabazón neokantiana de El alma y las formas, la cuestión se responde de manera negativa. El Märchen se vincula allí a un estado no empírico en el que las 
El concepto de Märchen (cuento maravilloso) en la obra temprana de György Lukács Francisco Garcia Chicote

cosas se entremezclan con los valores (LUKÁCS, 1985a, p. 50). La rígida distinción neokantiana entre esferas axiológica y objetiva se deshace en el Märchen, pues allí "cada pregunta se convierte en una cosa, parecida a la que le dio origen" (LUKÁCS, 1985a, p. 20; el destacado es nuestro). A este rebasamiento no empírico de la supuesta esencia subjetiva de los valores, el consecuente anclaje de estos en los objetos, se le suma un elemento utópico: el mundo del Märchen sugiere un deseo primigenio de satisfacción total, un "arcaico sueño de la edad de oro" (IBÍD., p. 86).

Sin embargo, en otros ensayos del mismo período, la pregunta por la posibilidad efectiva del mundo que configura el Märchen es respondida de modo afirmativo. Por ejemplo, la cuestión utópica de la existencia feliz es tratada en un manuscrito incompleto de 1910-1911, “La estética del 'romance'. Tentativa para una fundamentación metafísica de la forma del drama no trágico", que define conceptualmente un género contrapuesto a la tragedia, que Lukács pensó oportunamente en llamar "Märchendrama", "drama maravilloso" (cf. LUKÁCS, 1982, p. 148). Para Lukács, el "romance" o drama no trágico es un correlato complejizado del Märchen. Como en él, triunfa el final feliz y las rígidas divisiones que rigen la realidad vivencial se disuelven: "se entrecruzan, mezclan y alternan diversos niveles de realidad, ninguno de los cuales puede aspirar a un derecho de validez absoluta. Próspero dice: We are such stuff/As dreams are made on..." (LUKÁCS, 2015, p. 150). No sorprende pues, que The Tempest figure entre los ejemplares del "romance" y que se evidencie el vínculo sugerido en la frase de Balázs citada arriba. En virtud del final feliz como elemento rector y del carácter normal, natural de lo absurdo y la maravilla en estos cuentos, se trataría en ellos de una "consumación radiantemente absurda y obvia del anhelo terrenal-humano más profundamente universal: el anhelo de la felicidad vital" (IBÍD., p. 138). Un sueño arcaico y profundo, que subsistiría en la disposición infantil para la alegría, y cobraría realidad en el Märchen. Este es el tenor general con el que, por cierto también esporádicamente, aparece el Märchen en La teoría de la novela, escrita en el invierno de 1914-1915. Se lee allí que 
El concepto de Märchen (cuento maravilloso) en la obra temprana de György Lukács Francisco Garcia Chicote

estos cuentos conservan "fragmentos de mundos perdidos", en los cuales "lo que hoy solo se puede alcanzar utópicamente estaba presente en visibilidad visionaria" (1985a, p. 314).

Si bien no con el rango de un canon de la poesía, el Märchen parece haberse tornado en una suerte de piedra de toque en la búsqueda de géneros que complejizaran empíricamente el principio de la felicidad humana. Es decir, que configuraran materiales empíricos de un modo que la relación sujeto-objeto no condujese a la muerte o a una vida sin sentido. Además del ya mencionado "romance" o drama no trágico, el drama de gracia, la épica caballeresca y, finalmente, la narrativa de Dostoievski fueron analizados como portadores del principio del Märchen, como pruebas de que el presupuesto metafísico último de la tragedia, el hecho de que la escena en la que se juega nuestra existencia haya sido totalmente abandonada por los dioses (1985a, p. 246) no se corresponde con la verdad. Estos géneros prueban, de hecho, que "la divinidad no domina desde el más allá trascendente e inconcebible, sino que se torna para el menesteroso incluso acontecimiento, en algo que deviene, en una redención" (GLW 1, p. 616). La postulación de la presencia de la divinidad en el mundo pone necesariamente en entredicho el concepto negativo de forma que cimenta la tragedia. Para Lukács, la forma en tanto configuración del yo inteligible no se aviene con un género en el que se trata precisamente de la superación del dualismo presupuesto detrás de ese yo, y por ende un género en el que el punto de partida es la riqueza de la cotidianidad. Pero tampoco podía explicarse la forma como mera expresión de la época: en su proximidad a la vida, el Märchen habilita el condicionamiento histórico-objetivo de las formas, a la vez que insiste en la irrebasable dignidad humana, por más que esta vista el confuso término de "divinidad".

Así es que estrictamente se contraponen Märchen y tragedia. Son antitéticos los principios motores que aglutinan los acontecimientos: en un extremo, la muerte del héroe trágico constituye el punto álgido de su existencia, la confirmación de su vida en tanto vida auténtica; en el otro, el final feliz domina 
El concepto de Märchen (cuento maravilloso) en la obra temprana de György Lukács Francisco Garcia Chicote

la estructura narrativa, todo elemento ha de someterse a este principio y adquiere su sentido de él. El happy end se alcanza por medio de una serie de acontecimientos absurdos, pues la categoría que estructura el mundo configurado es la de una posibilidad radical: todo es igualmente posible y, por ello, el destino no existe como tal. En la tragedia, en cambio, la muerte se despliega a partir de una serie necesaria de pseudoacciones, cuyo punto de partida es la oposición entre la pureza del héroe que aspira al encuentro con Dios y la irreligiosidad de lo empírico. Se trata de algo cuya necesidad no es puesta subjetivamente, sino que pertenece al plano de la esencia (cf. IBÍD., p. 250s.). Un tercer elemento que aleja al Märchen de la profundidad interior de la tragedia es su carácter chato, bidimensional, propio del modo de presentación de los frisos, cercano incluso a lo decorativo. El Märchen parece ser el superviviente simplificado y la mera indicación utópica de una relación sujeto-objeto cuyo recíproco condicionamiento augura la felicidad de la humanidad.

Estas características formales del género sirvieron de fundamento para el primero de los trabajos de Lukács sobre cine, "Reflexiones sobre una estética del 'cine"', escrito, como el trabajo sobre el "romance", también hacia 1911. Si bien una determinación exhaustiva de este problema rebasaría el objeto del presente trabajo, cabe al menos constatar una serie de factores que evidencian esta afinidad entre cine y Märchen. Para el filósofo, el principium stilisationis del cine representa la vida entera en un mismo nivel, sin referencia a ninguna profundidad metafísica, bidimensional: sus personajes son series de acciones en movimiento más que caracteres con personalidad. Serie de acciones cuya movilidad permea toda las cosas: la esencia del cine es "el movimiento propiamente dicho, la eterna alterabilidad, el continuo cambio de las cosas" (LUKÁCS, 1989, p. 72). Además, le es dada al cine la facultad de poetizar cosas (tales como los adelantos de la técnica) que no tendrían cabida en otras artes; hay en el cine un elemento de la potencia artística arcaica que aún residiría en los niños: "el niño, vivo en todo ser humano, queda en libertad y se 
El concepto de Märchen (cuento maravilloso) en la obra temprana de György Lukács Francisco Garcia Chicote

convierte en el amo de la psyché del espectador" (IBíD., p. 74). Se sigue de ello que, como en el Märchen, la categoría rectora del arte cinematográfico sea la posibilidad radical: “De este modo surge en el 'cine' un mundo nuevo, homogéneo y armonioso, uniforme y rico en cambios, al cual corresponden en los mundos de la literatura y de la vida el Märchen y el sueño" (IBÍD., p. 73).

Sintomático del estado de las consideraciones lukácsianas sobre el tema en cuestión es que, una vez hecha evidente la afinidad entre Märchen y cine, se afirme que aún le falte a este el surgimiento de un artista que le haga honor a las potencialidades configuradoras del medio: un "Hoffmann o Poe", un "Arnim o [...] Barbey d'Aurevilly" (IBÍD., p. 75). En efecto, a la ausencia de delimitaciones claras entre, por ejemplo, el cuento maravilloso sensu stricto y otras formas narrativas breves ${ }^{3}$ se le suma una cierta confusión frente a aquella diferencia que Jakob Grimm había defendido ante Arnim y que delimitaría cualitativamente los ámbitos de la Volkspoesie (poesía popular) y la Kunstpoesie (poesía de artista) (cf. JOLLES, 1956, p. 183). ${ }^{4}$ Si bien, como se verá inmediatamente, en 1918 Lukács emprende una tentativa de delimitación inequívoca entre mito, Märchen y géneros fantásticos y esboza cierta distinción entre géneros tradicionales y formas modernas, esta última continúa siendo, en todo el período analizado por estas líneas, abstracta.

\section{El Märchen como expresión de la crisis mundial}

En 1918 aparece el primer y único ensayo de Lukács dedicado exclusivamente al género: "Siete Märchen". La pieza pretende reseñar la obra literaria homónima de Balázs, publicada el mismo

\footnotetext{
3 Ausencia que se halla en la base de las compilaciones de Jakob y Wilhelm Grimm, tal como señaló Jolles (1956, p. 181). El carácter heterogéneo del "género Grimm" es remarcado por Heinz Rölleke (1992, p. 37), para quien muchos de los textos de la antología de los hermanos Grimm presentan aspectos de sagas, leyendas, fábulas y solo el grupo más pequeño lo conforman los "así llamados cuentos maravillosos".

4 Aquí no ignoramos que, como advierten Mayer y Tismar (2003, p. 2s.), no se puede pretender ya una clara distinción entre uno y otro ámbito; simplemente nos remitimos al hecho de que Volksmärchen (cuento maravilloso popular) y Kunstmärchen (cuento maravilloso de artista) manifiestan diferencias formales que pueden ser subsumidas en la "conciencia de una distancia" que rige los últimos, es decir, una "disociación en la estructura de lo narrado".
} 
El concepto de Märchen (cuento maravilloso) en la obra temprana de György Lukács Francisco Garcia Chicote

año. En su ensayo, Lukács retoma muchas de las determinaciones anteriores, a la vez que emprende una definición abarcadora del principio de estilización del género. Se lo delimita frente a otras formas de la literatura y se caracteriza la peculiaridad de sus manifestaciones modernas; además, el Märchen se concibe como prueba, como indicación del carácter contingente de las relaciones burguesas, es decir, como "revelación de que toda nuestra vida es, en tanto totalidad, azar" (GLW 1, p. 739).

Si en las reflexiones anteriores el género parecía importar ante todo como principio poético en la búsqueda y fundamentación de otras formas de la literatura, aquí asume un estatuto peculiarmente autónomo. Ilustrativa de esta situación es la comparación provista por el autor: el Märchen se comportaría frente a los demás géneros como la geometría no euclidiana frente a la euclidiana. Los otros géneros develan las bases de una existencia humana -la nuestrasumida en el caos y la confusión de la vida; el Märchen representa un mundo con otras bases.

Valiéndose de esta radicalidad maravillosa y anticipándose a estudios de otros teóricos, Lukács distingue lo maravilloso de lo fantástico. El horror causado por la configuración fantástica provendría de un lejano sentimiento de familiaridad, del darse cuenta de que una conexión ha sido perdida: "[l]o horroroso en lo fantasmagórico resulta del parentesco entre algo que traspasa nuestra empiria y nosotros; resulta del sentimiento estremecedor de que lo que es totalmente inasible [...] es regido por las leyes de nuestro ser" (GLW 1, p. 741). La falta de vínculo entre lo configurado en el Märchen y los planos empíricos y metafísicos de nuestra existencia es absoluta, y por ende lo que allí se manifiesta carecería necesariamente de todo lo horrible y espantoso. Más allá de que se halle dañada en algún aspecto, es una estructura religiosa, metafísica, del mundo la supuesta por lo fantástico; en cambio, el espíritu que insufla el Märchen lleva por nombre "magia" y supone la aparición, el encuentro inmediato, no procesual de un "nuevo absoluto": 
El concepto de Märchen (cuento maravilloso) en la obra temprana de György Lukács Francisco Garcia Chicote

Por ello no hay en el concepto de lo "nuevo" en el cuento maravilloso ninguna antítesis. Todo otro "nuevo" surge del tiempo y se encuentra puesto dentro de una realidad temporal: es por lo tanto nuevo en relación con algo otro. Lo nuevo del cuento maravilloso es por el contrario absoluto; es el resultado de un encontrar [Auffinden] y no del inventar [Erfinden]. Es el encontrar algo que siempre ha habido (o algo, lo que aquí equivale completamente, que nunca y en ningún lugar ha habido), que se enfrenta empero a toda nuestra realidad como algo radicalmente nuevo y cuya condición de nuevo -porque sus raíces yacen en su esencia y no en su situación- no puede terminar o desvanecerse (GLW, p. 741). ${ }^{5}$

Igual de novedosa pero significativamente más problemática es la distinción entre manifestaciones tradicionales y modernas. Lukács conceptualiza tal diferencia, pero no considera las formas modernas como configuraciones que solo pueden plasmar la maravilla de modo irónico o desgarrado. Es decir, no comprende la modernidad del género en la clave crítico-negativa con la que comprende las otras formas, sino en términos afirmativos. El Märchen de nuestra época ha de plasmar la totalidad de manera compleja y sin contradicciones, lo que lo vuelve, según Lukács, una forma adecuada para el desarrollo no alienado de la infinita interioridad subjetiva: "La infinitud del Märchen que se ha vuelto de este modo nuevamente posible es por tanto la infinitud interior del alma y no la del mundo, con en los antiguos Märchen" (GLW 1, p. 748). La variante nueva sería así capaz de configurar una forma de la individualidad que retendría la profundidad subjetiva moderna sin acarrear por ello las implicancias de la alienación; esto es lo que el Lukács de La teoría de la novela había designado "realidad anímica" (Seelenwirklichkeit) para definir el supuesto logro de la épica de Dostoievski. ${ }^{6}$

\footnotetext{
5 Destacan aquí afinidades con el análisis de Sigmund Freud, de 1919, de lo ominoso, categoría abstraída en parte de los relatos fantásticos. Por un lado, Freud concibe también el mecanismo básico de lo fantástico como el resultado de una violencia infringida sobre un vínculo familiar que retorna; reconoce por otro lado la peculiaridad del Märchen, por más que ocurran en él tematizaciones en apariencia ominosas (cf. 1986, p. 249).

6 Lukács (1985a, p. 419) define la "realidad anímica" como una esfera "la cual aparece el ser humano como ser humano -y no como ser social, pero tampoco como interioridad aislada e incomparable, pura y, consiguientemente, abstracta-, una en la cual [...] se podrá contruir una totalidad nueva y redondeada.
} 
El concepto de Märchen (cuento maravilloso) en la obra temprana de György Lukács Francisco Garcia Chicote

Aparece aquí una limitación profunda de la intrincada estructura teórica del joven filósofo. Al indicar el carácter positivo, no irónico de la forma moderna del Märchen, Lukács revela que su idea de superación de la existencia burguesa se funda aún en un esquema de alternativas estrictamente excluyentes que no incorpora una categoría dialéctica de mediación. Conceptualmente, el Märchen postula una situación en la que forma y material son polos dialécticos de la misma unidad; pero dado que dicha reciprocidad dialéctica se consigue a causa de la atemporalidad del género, cada vez que este ha de vérselas con un material temporal (como resulta indudable en el caso de la variante moderna) acaba hipostasiándolo. De ahí que, en la práctica, este concepto resulte inviable: la positividad del Märchen depende, en última instancia, de la ahistoricidad de sus formas $y$, consecuentemente, de un vínculo contingente con los materiales que moldea, a la vez que, dado su carácter afirmativo, no tematiza tal contingencia. En cierta medida, la definición del Märchen como lo radicalmente nuevo confirma la vigencia de un enfoque en Lukács -quien recién tres años más tarde comprendería la transformación democrática de las relaciones burguesas como "la manifestación de la estructura cósica, objetiva y propia de esos objetos mismos" (LUKÁCS, 1969, p. 180)- que circunscribe la configuración de lo utópico dentro de los dudosos y ante todo contingentes límites de un juicio axiológico, de un deber ser.

Es consecuente que se agudice al extremo aquella vacilación, señalada arriba, respecto de la posibilidad de que el mundo de estos cuentos cobre realidad empírica. Por un lado, se afirma que el Märchen ocurre en un plano de realidad en el cual los fundamentos de nuestra existencia no detentan validez alguna. Por otro, se recuerda que "el mundo del Märchen no es ninguna realidad" (GLW 1, p. 740). El principio maravilloso de estilización prueba la posibilidad de una realidad tal porque solo puede ser expresión de ella (es decir, porque existe el Märchen, su mundo es posible), pero el mundo del Märchen no es realidad porque la estructura necesariamente doble de lo real, que incluye los 
El concepto de Märchen (cuento maravilloso) en la obra temprana de György Lukács Francisco Garcia Chicote

planos empírico y metafísico, carece de todo sentido en él. Esta vacilación, que se desprende de la comprensión no dialéctica de la forma y los materiales, no impide que Lukács divise en el Märchen el fundamento para un programa de la transformación efectiva, total y material. La potencia redentora del Märchen es idiosincrásicamente imparable: se halla impulsada por una melancolía fina pero profunda, apenas perceptible y "nunca sentimental", la melancolía de una liberación que avanza en dos direcciones. Por un lado, el Märchen prueba que una "satisfacción completa del ser" es materialmente representable. Por el otro, su mera existencia le confiere al estado efectivo de las cosas -esto es, a la realidad en que vivimos- el carácter de haber resultado de una elección. El Märchen otorga

la conciencia de que la realidad -tanto la empírica como la metafísica- en la que vivimos no es la única posible, sino solo una entre las ilimitadamente variadas realidades imaginables; la conciencia de que nosotros, aunque -por los motivos ya aducidos-solo nuestra realidad puedaser para nosotros de hecho realidad, podamos verla más como un simple juego intelectual, más como fantasía, como una entre las infinitamente posibles. Pues con ello se supera de un golpe el hecho de que sintamos nuestra realidad como una cárcel: si somos capaces -por cierto solo en pensamientos, pero no ociosos ni irresponsables- de vivir también otras realidades completamente, hasta la satisfacción, el carácter privilegiado de la nuestra recibe entonces un nuevo acento: el acento de la elección; entonces nuestra realidad ya no puede ser más cárcel para nosotros (GLW 1: 744).

Igualmente sintomática de esta superación sin mediación es la explicación sociológica de la emergencia del Märchen. Estos cuentos aparecerían en épocas de "distensión" de los fundamentos de la realidad, épocas "en las que parece como si uno estuviese colocado nuevamente frente a una elección, como si uno debiera nuevamente decidir acerca de si ha de permanecer en el camino 
El concepto de Märchen (cuento maravilloso) en la obra temprana de György Lukács Francisco Garcia Chicote

una vez tomado de nuestra realidad o si pisa un sendero que, de acuerdo con su esencia, le es ajeno a uno" (GLW 1, p. 747). Tales tiempos de crisis preludian para Lukács una suerte de nuevo estado de agregación de la materia, una vez que las viejas y entumecidas formas se "distienden".7 Sin embargo, a la constatación de la crisis y de sus potencialidades le sigue inmediatamente la restricción del alcance de tal "distensión":

Ciertamente, la oportunidad de una tal elección es solo apariencia: vivimos pues en tiempos de crisis de nuestra realidad. Son las posibilidades de nuestra realidad las que se bifurcan frente a nosotros en una encrucijada; independientemente de cuál de los caminos emprendiéramos, este nunca nos llevaría fuera de nuestra realidad (GLW 1, p. 747).

Las vacilaciones provenientes de este enfoque no dialéctico encontraron una solución sin que sus términos fuesen superados, es decir, una solución no dialéctica. A partir de la proclamación de la República de los consejos en marzo de 1919, Lukács se convenció de que el mundo del Märchen podía y debía cobrar realidad empírica.

\section{El Märchen en la República de los consejos}

La adhesión, hacia mediados de diciembre de 1918, de Lukács al recién formado Partido Comunista húngaro trajo consigo la consolidación, en su pensamiento, de por lo menos tres complejos de enfoques teóricos. Cabe señalar, en primer lugar, la convicción de que la historia no es, como parece deducirse de la dinámica del drama trágico, impulsada por conflictos irresolubles entre posiciones morales de individuos heroicos. Ahora, para Lukács, el sujeto de la historia son las masas (cf. KADARKAY, 1994, p. 345).

7 Ciertamente, un diagnóstico sociopolítico deudor del vitalismo simmeliano (compárese, por ejemplo, el ensayo contemporáneo de Simmel "El conflicto de la cultura moderna"). 
El concepto de Märchen (cuento maravilloso) en la obra temprana de György Lukács Francisco Garcia Chicote

En segundo término, la afirmación de que el principio redentor no solo era inmanente y debía por tanto buscarse y encontrarse en la vida condujo a una modificación del concepto de cultura. Lukács ya no la concibe alternativamente o como una dignidad aristocrática de la muerte (así lo hace en su El alma y las formas) o como una mendaz frivolidad (así lo hace en "Cultura estética"), sino que recupera el optimismo humanista que la noción de cultura había adquirido en la llustración alemana. El 17 de abril, ya al mando del Comisariado popular de educación, afirmó programáticamente: “La política es meramente el medio, la cultura es la finalidad" (LUKÁCS, 1975, p. 94). En tercera instancia, se manifiesta en este contexto una genuina preocupación pedagógica para la formación de esta "nueva cultura" (IBÍD., p. 146). La frenética labor del Comisariado da cuenta de la seriedad con que se asumió esta tarea: desde un comienzo, sus programas no buscan la imposición de valores culturales, sino la creación de un marco en el que la cultura pueda surgir sin condicionamientos ni compromisos. En vista de tal fin, cobra interés prioritario para Lukács y los ahora igualmente funcionarios Lesznai y Balázs la educación de los niños. El Märchen cumplirá un rol principal en la formación de niños en seres culturales. Conocida es la resolución del 15 de abril que exhorta a los directores de escuela a comparecer "incondicionalmente" en las oficinas del Comisariado para ser aleccionados acerca de cómo han de utilizar Märchen en las aulas (cf. aviso periodístico de la resolución en IBÍD., p. 274); se sabe también que Balázs instruyó que narradores del Comisariado contaran cuentos a niñas y niños en hospitales, escuelas y barrios dos tardes por semana; Gángó (2014, p. 61) y Loewy (1999, p. 297) informan sobre la creación, al interior de la estructura burocrática del Comisariado, en abril de 1919 de un "Departamento" del Märchen a cargo de Lesznai; Illés, József y Szabolcsi (1984, p. 402) afirman que en julio de 1919, el Comisariado llamó a un concurso de escritores de Märchen, que habrían de nutrir las narraciones públicas.

El giro político de Lukács no significó empero la caída del paradigma trágico, sino que en la nueva comprensión del mundo 
El concepto de Märchen (cuento maravilloso) en la obra temprana de György Lukács Francisco Garcia Chicote

este coexistió con (e incluso fue llamado a asegurar y ganar) el espacio cultural a cuyo desarrollo contribuía el Märchen. Es decir, aquel enfoque de alternativas no dialécticas que hasta 1918 acarreaba vacilaciones ofrece ahora los cimientos teóricos de un resuelto programa político. Elocuente de esta nueva combinación de enfoques opuestos que antes solo se permitían alternativamente es la imagen de marco. La política revolucionaria, las medidas económicas, la defensa militar frente al avance de los ejércitos del Entente (en suma, todas aquellas actividades de esferas subsumidas en el concepto de civilización) exigían a los ojos del filósofo -y de sus funcionarios- una ética sacrificial, violenta, pecaminosa, propia de su concepto de tragedia, que debía resguardar y velar por un espacio cualitativamente diferente, libre de compromisos, anticipado y promovido por el Märchen. "Pues debe darse que la llama arda en un lugar de manera totalmente pura, que la lucha por los intereses del proletariado sea sin compromisos, completamente pura, intachable", advierte Lukács ante el Congreso de jóvenes trabajadores en junio de 1919 (LUKÁCS, 1975, p. 152). Sin el "marco social" (IBÍD., p. 87) procurado por la actividad revolucionaria pecaminosa resultan vanos los intentos de despliegue cultural, pues este ha de tener un desarrollo propio, libre, no contaminado. Es pues consecuente que en su descargo ante la denuncia de usar fondos públicos para la promoción del Märchen, Balázs comparase a los revolucionarios con Moisés, cuya misión es llevar al pueblo de Dios de retorno a su hogar, pero no entrar en él (BALÁZS, 1984, p. 124). ${ }^{8}$

La primera fase comunista de Lukács se halla signada por una modificación del concepto de cultura. El documento programático del Comisariado, "La vieja y la nueva escuela. La liberación de la educación popular y la comunidad del trabajo y el juego en la educación de los niños", concluye en efecto con el siguiente dictum: "El comunismo significa la adopción [Übernahme] de la cultura en la propiedad pública" (en LUKÁCS, 1975, p. 265). Esto significa la

\footnotetext{
8 Löwy (1979, p. 80s.) muestra la impronta en esta conceptualización de la tarea revolucionaria de las ideas de Erwin Szabó, “el guía espiritual del socialismo revolucionario en Hungría"; el rigorismo moral que caracterizaba al grupo de Lukács, su comprensión de la actividad revolucionaria como emplazamiento sin mediaciones de fines ya delineados idealmente habrían propiciado la recepción de los enfoques izquierdistas de Szabó.
} 
El concepto de Märchen (cuento maravilloso) en la obra temprana de György Lukács Francisco Garcia Chicote

superación del carácter irremediablemente privado-particular que las prácticas y productos subsumidos en el concepto de cultura cobran necesariamente bajo la lógica del orden burgués; Lukács confiaba en que los cambios económicos y políticos posibilitarían el emplazamiento de una cultura auténtica. El filósofo, que ya había criticado las determinaciones de la cultura burguesa en el ya mencionado ensayo "Cultura estética", de 1911, las comprendía ahora como expresiones del modo capitalista de producción.

El ensayo que resume esta posición es "Vieja y nueva cultura". Se define allí el orden político-económico socialista como un medio para la existencia cultural, esto es, para la posición del ser humano como "fin en sí" (Lukács, 1974, p. 86). Lukács rechaza el economicismo determinista que supone que Marx divide el ser social entre una "base" y una "superestructura" (IBÍD., p. 81s.). Además, comprende que la peculiaridad del capitalismo no reside en la relación interpersonal de dominio mediada por la propiedad de los medios de producción, sino en la dinámica específica de valorizaciónexpansivaquesubordinatodaslasclases:"elcapitalismo ha vuelto [a las clases dominantes] esclavas de la producción de manera similar a como lo ha hecho con los trabajadores, aunque concediendo un valor bien distinto a su esclavitud" (IBÍD., p. 75). De ahí que Lukács entienda que la superación del capitalismo no significa la supresión del dominio de una clase sobre otra, sino "la liberación del dominio de la economía" (íd.). Al suprimir la forma mercancía, el socialismo cumpliría con el "presupuesto sociológico de la cultura": el ser humano como fin en sí mismo, el carácter consciente de la división del trabajo (IBÍD., p. 83). Por ello, resultaría "ridículo" anticipar cómo sería el mundo cultural, pues la transformación socialista de la sociedad conforma "solo el marco, sola la posibilidad de la libre autorrealización, de la espontánea fuerza creadora de los seres humanos" (IBíD., p. 85).

El Märchen constituye una herramienta eficaz en la formación del nuevo individuo, del ser humano cultural; esto se debe al efecto que el género tendría en el sujeto privilegiado del Comisariado, su prioridad absoluta: el niño. 
El concepto de Märchen (cuento maravilloso) en la obra temprana de György Lukács Francisco Garcia Chicote

En su réplica a la acusación de gastar fondos públicos en Märchen, Balázs, director de la sección de literatura del Comisariado, declama: “iEl niño ante todo!”. El niño es la garantía de la realización del comunismo, y por ello no ha de repararse en costos cuando se trata de su formación (1984, p. 124). "Contra los niños no hay lucha de clases, pues todos los niños deben ser considerados como miembros fundantes de una sociedad venidera", afirma Lukács a mediados de abril de 1919 (1975, p. 88). ${ }^{9}$ Dos son los motivos con los que se justifica tal privilegio. De una parte, a raíz de su corta vida, el niño no se halla contaminado por las formas burguesas; no hay determinaciones de clase, no hay penetración de la división abstracta del trabajo en su alma. De otra parte, el niño conserva características puramente humanas, independientemente de si es consciente o no de ellas: posee, por ejemplo, una inclinación inmediata al arte y un concepto connatural de género artístico. Pero ante todo, desarrolla una sociabilidad "comunitaria", de amor, satisfacción y felicidad. El programa educativo del Comisariado la concibe en estos términos: "Pues los niños tienen su propia sociedad, su propio mundo [...]. Un mundo especial, alegre, diáfano, sonriente, en el que viven conjuntamente en comunidad feliz en sus hogares saludables, en sus campiñas alegres" (IBÍD., p. 260).

Rige aquí un concepto idealista de niñez que se remonta a las ideas de la segunda llustración y el primer romanticismo alemán: en virtud de propiedades desalienantes, el niño ofrece un ideal de sociabilidad. ${ }^{10}$ Además, incide en esta concepción un estricto esquema dualista, por el cual nada de la sociedad burguesa excepto sus productos culturales- ha de considerarse digno y todo contacto con las formaciones de la civilización corrompe la pureza del alma. Incide, finalmente, también aquella cosmovisión mesiánica, mencionada arriba, que cargaba a la redención con un valor restitutivo: en cierto sentido, la meta es el comienzo. Así visto,

9 Gángó (2014, p. 62) sostiene que el artículo del que se halla tomado este pasaje presenta “las bases teóricas" de la poética del Märchen durante la República de los consejos.

10 Cf. el estudio de Hans-Heino Ewers sobre el concepto de niñez en el primer romanticismo alemán. De acuerdo con Ewers (1984, p. 25), “[a] causa de su participación en el futuro y en el pasado, los niños adquieren una función mediadora para los adultos: ellos son para estos representaciones, concretizaciones del propio origen como del propio futuro. Porque de este modo la niñez no solo posee un carácter arcaico sino también uno futurístico, alcanza para los adultos el significado de un ideal al cual siguen vinculados aun incluso como adultos". 
El concepto de Märchen (cuento maravilloso) en la obra temprana de György Lukács Francisco Garcia Chicote

el niño justifica la lucha que deviene necesariamente pecaminosa, pues de lo que se trata es de asegurar a cualquier precio su desarrollo libre, su despliegue sin compromisos. La educación comunista ha de cultivar la humanidad del niño y, de ese modo, diferenciarse tajantemente de la "vieja escuela", que deformaba a las personas conforme los atributos productivos que, en virtud de una división alienante del trabajo, debía inculcarles: "Ya solo por su sistema educativo, la sociedad capitalista se merece la muerte" (IBÍD., p. 260).

Al referir, en su novela autobiográfica, el momento en que su grupo toma el poder del Comisariado, Lesznai recuerda que "Ileva[ban] años planificando la remodelación del Märchen" (cit. por GÁNGÓ, 2014, p. 61). En efecto: ya en "Enseñanza del arte en la escuela", de 1911, Lukács insistía en que la restitución del contacto vivo con el arte, perdido en la sociedad burguesa, solo podía llevarse a cabo por medio de la educación, en especial la de los niños, pues en ellos subsistía un sentido nato, intuitivo para la estética. Tal receptividad a las artes se manifiesta, para Lukács, en el vínculo de los niños con el Märchen: "la relación de los niños con los cuentos maravillosos es más pura, más profunda y más específicamente artística que la de la mayoría de los adultos con su novela favorita o su poema favorito [...;] los niños entrevén [...] más intensamente las cuestiones últimas de la forma" (GLW 1, p. 385). Lukács destaca aquí que los niños no se relacionan con los cuentos como con cosas susceptibles de ser poseídas: prueba de ello es que pidan siempre que se les narre el mismo cuento, no uno nuevo. Se manifiesta asimismo en este vínculo una auténtica actitud crítica: las leyes del género constituyen el criterio de valoración de los cuentos; de allí que rechacen aquellos ejemplares que no cumplan con las formas de la estilización (un final claro, feliz). Esta línea interpretativa es retomada por Balázs en 1919 al defender la política del comisariado. Hay una afinidad entre la vivencia infantil y la estilización de los cuentos: por más que uno quiera enseñarle teoría marxista, afirma, "el niño ve cuentos maravillosos alrededor suyo, para el niño todo objeto es viviente" (BALÁZS 1984, p. 125). 
El concepto de Märchen (cuento maravilloso) en la obra temprana de György Lukács Francisco Garcia Chicote

Pero esta inclinación por la fantasía maravillosa confirma la posiblidad de una existencia verdaderamente humana: en virtud de su ancestralidad, en virtud de su indiferencia respecto de las formas históricamente circunstanciales de la alienación, el mundo del Märchen alcanza, para Balázs, en el mayor de los grados las metas del comunismo:

\begin{abstract}
Un mundo en el que de todas las cosas pueda surgir todo con arreglo a su valor interior, donde las figuras no solo confundan la clase, sino también la forma y la vida... eso es más comunista que nuestro comunismo. Nosotros solo hemos eliminado la diferencia entre las clases humanas, el cuento maravilloso ha superado, por medio de la posibilidad de la magia, los límites entre animales, plantas, seres humanos, todos los seres existentes y no existentes (1984, p. 126).
\end{abstract}

La muerte de la República en manos de los ejércitos del Entente significó la caída de los programas que promovían el Märchen. La ardua investigación que comenzó con esta etapa de exilio en Lukács, y que significó ante todo la incorporación de la categoría de mediación, podría explicar por qué cayó también el andamiaje teórico que sostenía la poética de estos relatos.

\title{
6 Conclusiones
}

Los alcances de la investigación expuesta en las líneas precedentes pueden sintetizarse en tres aspectos. Primero: el Märchen se concibe como prueba y laboratorio de una concepción del mundo que se contrapone al estricto dualismo propio del pensamiento social centroeuropeo del último cuarto del siglo XIX y primeras décadas del XX. Segundo: el Märchen asume un papel modélico en el armado de una constelación de géneros narrativos (y dramáticos) y en la definición de criterios críticos para ella. A 
El concepto de Märchen (cuento maravilloso) en la obra temprana de György Lukács Francisco Garcia Chicote

su vez, se rechazan concepciones unilaterales de la forma: esta no es ni la cristalización de una subjetividad metafísicamente hipostasiada ni el reflejo directo de dinámicas históricas, sino que se la entiende, si bien aún de manera confusa, como resultante de un cruce entre un modo propiamente humano de actividad y determinaciones históricas. Tercero: el Märchen se propone como prueba y medio para el surgimiento de la cultura, un mundo auténtica y dignamente humano. En este sentido, la poética del Märchen elaborada por Lukács y sus amigos condiciona significativamente sus primeras concepciones del socialismo como modo de sociabilidad, impregnadas de tintes mesiánicos.

Estos tres elementos del concepto de Märchen encuentran empero su limitación en el hecho de que su validez se halla subjetivamente postulada. La poética del género muestra en efecto que Lukács y sus colegas llegaron por medio de él a atisbar una serie de implicancias teórico-metodológicas encaminadas hacia la pregunta por la posibilidad de la dignidad humana, pero circunscribieron la validez de sus hallazgos a un género cuya ligazón con la sociedad burguesa, con la realidad histórico-concreta, celosamente cercenaron (como se ha visto: el Märchen es a los otros géneros lo que la geometría no euclidiana es a la euclidiana). Sin una categoría de mediación, la posibilidad del Märchen depende entonces del aniquilamiento de la vida efectivamente existente: en términos lógicos, eso significa el regreso victorioso del ethos trágico. La primera teoría política de Lukács, que justificaba el sacrificio personal y la eliminación sin miramientos de la empiria burguesa con la necesidad de que el mundo de la cultura surgiera sin compromisos, presenta una dinámica coherente con tal definición. La emergencia, en el pensamiento lukácsiano, de la categoría de mediación como palanca central de la praxis tornaría obsoleta su propia poética del Märchen. 
El concepto de Märchen (cuento maravilloso) en la obra temprana de György Lukács Francisco Garcia Chicote

\section{Referencias}

BALÁZS, Béla. Nehmt den Kindern nicht das Märchen. In: ILLÉS, László et al., Befunde und Entwürfe. Zur Entwicklung der ungarischen marxistischen Literaturkritik und Literaturtheorie (1900-1945). Berlin: Akademie-Verlag, 1984, 124-127.

BALÁZS, Béla. Notes from a Diary, The New Hungarian Quarterly, XIII, 124-128, 1972.

EWERS, Hans-Heino. Einleitung. In: EWERS, Hans-Heino (ed.), Kinderund Jugendliteratur der Romantik. Stuttgart: Philipp Reclam, 1984, p. 7-58.

FEHÉR, Ferenc. The Pan- Tragic Vision: The Metaphysics of Tragedy, New Literary History, n. 11, p. 245-254, 1980.

FEKETE, Eva; KARÁDI, Eva. Georg Lukács. Sein Leben in Bildern, Selbstzeugnissen und Dokumenten. Budapest: Corvina Kiadó, 1981. FREUD, Sigmund. De la historia de una neurosis infantil (El "hombre de los lobos") y otras obras. 1917-1919. Obras completas vol. XVII. Buenos Aires: Amorrurtu, 1986.

GÁNGÓ, Gangó. El cuento de hadas como llustración, cultura y violencia. In: HERNÁNDEZ, Isabel; LLAMAS, María (eds.), Los hermanos Grimm en contexto. Madrid: Síntesis, 2014, 55-65.

GÁNGÓ, Gangó. La política cultural de la República soviética húngara. In: LUKÁCS, György, Derrotismo y dialéctica. Buenos Aires: Herramienta, 2015, 135-146.

ILLÉS, László et al. (eds.). Befunde und Entwürfe. Zur Entwicklung der ungarischen marxistischen Literaturkritik und Literaturtheorie (1900-1945). Berlin: Akademie-Verlag, 1984.

JOLLES, André. Einfache Formen. Halle: Max Niemeyer Verlag, 1956. KADARKAY, Arpad. Georg Lukács. Valencia: Edicions Alfons el Magnànim, 1994. 
El concepto de Märchen (cuento maravilloso) en la obra temprana de György Lukács Francisco Garcia Chicote

KAMMLER, Jörg. Politische Theorie von Georg Lukács. Darmstadt, Neuwied: Soziologische Texte 94 Luchterhand, 1974.

LENK, Kurt. Das tragische Bewußtsein in der deutschen Soziologie, Kölner Zeitschrift für Soziologie und Sozialspychologie, n. 16, p. 257287, 1964.

LESZNAI, Anna. Tagebuch (1912-1927). In: KARÁDI, Éva \& VEZÉR, Erzsébet (eds.), Georg Lukács, Karl Mannheim und der

Sonntagskreis. Frankfurt a.M.: Sendler 1985, 129-139.

LOEWY, Hanno. Medium und Initiation. Béla Balázs: Märchen, Ästhetik, Kino. Tesis doctoral. Universität Konstanz: Konstanz, 1999. LÖWY, Michael. Redención y utopía. El judaísmo libertario en Europa Central. Un estudio de afinidad electiva. Buenos Aires: El cielo por asalto, 1997.

LÖWY, Michael. Georg Lukács. From Romanticism to Bolshevism. London: NBL, 1979.

LUKÁCS, György. Acerca de la pobreza de espíritu y otros escritos de juventud. Buenos Aires: Gorla, 2015.

LUKÁCS, György. El alma y las formas. Teoría de la novela. Barcelona: Grijalbo 1985a.

LUKÁCS, György. Reflexiones sobre una estética del cine. In: LUKÁCS, György, Sociología de la literatura. Barcelona: Península, 1989, p. 71 77.

LUKÁCS, György. Briefwechsel 1902-1917. Budapest: Corvina Kiadó ,1982.

LUKÁCS, György. Historia y conciencia de clase. Barcelona: Grijalbo, 1969.

LUKÁCS, György. Taktik und Ethik. Politische Aufsätze I. Darmstadt, Neuwied: Luchterhand, 1975.

LUKÁCS, György. Werke (GLW). Neuwied \& Berlin: Luchterthand; Bielefeld: Aisthesis Verlag 1965-2018.

MÁRKUS, György. The Soul and Life: The Young Lukács and the Problem of Culture, Telos, 32, 95-115, 1977. 
El concepto de Märchen (cuento maravilloso) en la obra temprana de György Lukács Francisco Garcia Chicote

MAYER, Mathias; TISMAR, Jens. Kunstmärchen. Stuttgart, Weimar: Sammlung Metzler 155, 2003.

RÖLLEKE, Heinz. Die Märchen der Brüder Grimm. Bonn, Berlin: Bouvier Verlag 1992.

SIMMEL, Georg. Gesamtausgabe (GSG). Frankfurt a.M.: Suhrkamp, 1989-2016.

VEDDA, Miguel. Emancipación humana y "felicidad no disciplinada", Walter Benjamin y la poética del cuento de hadas. In: VEDDA, Miguel, La irrealidad de la desesperación. Estudios sobre Siegfried Kracauer y Walter Benjamin. Buenos Aires: Gorla, 2011, 103-118.

VEDDA, Miguel. Estudio Preliminar. Entre la metafísica y la historia. Sobre la trayectoria intelectual del joven Lukács. In: LUKÁCS, György, Acerca de la pobreza de espíritu y otros escritos de juventud. Buenos Aires: Gorla, 2015, p. 5-87. 